\title{
Experiential Learning for Enhancing Environmental Literacy Regarding Energy: A Professional Development Program for Inservice Science Teachers
}

\author{
Mark Bloom ${ }^{1 *}$, Sarah Quebec Fuentes ${ }^{2}$ \\ ${ }^{1}$ Dallas Baptist University, Dallas, USA \\ ${ }^{2}$ Texas Christian University, Fort Worth, Texas, USA
}

Received 18 May 2018 - Revised 18 December 2018 - Accepted 2 January 2019

\begin{abstract}
This article describes results of a professional development (PD) program for inservice science teachers. The PD integrated experiential learning to enhance participants' literacy regarding energy production and associated environmental costs. The PD focused on six energy sources and environmental politics that must be navigated to make decisions about their sustainability. Participants toured energy extraction/production sites including coal mines, hydroelectric dams, wind farms, and nuclear power plants. At each site, participants encountered differing perspectives on the environmental costs and benefits of the energy sources. Group discussions allowed for sharing participants' thoughts on each perspective and mathematical modeling was used as a tool for evaluating each energy source. Data included pre- and post-content assessments and PD evaluation surveys. Analysis revealed the role that experiential learning played in changed perspectives on energy production, content knowledge growth, and impacts on the participants' own classroom teaching.
\end{abstract}

Keywords: energy literacy, experiential learning, professional development, modeling

\section{INTRODUCTION}

Understanding the environmental and societal impacts of energy production in America is a critical component of environmental literacy. American energy needs are met by various sources including coal, natural gas, oil, hydroelectric, wind, and nuclear. Each source of energy presents distinct challenges and benefits to the natural environment and to society. Various stakeholders might possess distinctly different perspectives on each energy source depending on their political, economic, or social values (Bloom, Quebec Fuentes, Holden, \& Feille, 2015; Bybee, McCrae, \& Laurie, 2009). In the highly politicized climate in America regarding energy needs, it may be difficult to make sense of the contradictory claims made about diverse energy sources. Saylan and Blumstein (2011) indicate that educational institutions are partly to blame for failing to challenge students to critically analyze complex issues. Instead, students are accustomed to accepting "quickly expressed and easily digested" explanations that do not require deep contemplation (Saylan \& Blumstein, 2001, pp. 3-4). Unfortunately, these simplistic representations fail to adequately address problems that lack simple solutions (Klosterman, Sadler, \& Brown, 2012).

The present paper describes the implementation and evaluation of a professional development (PD) program for inservice science teachers. The goal of the PD was to guide participants in critically analyzing six distinct sources of energy to determine their relative environmental impacts. The PD incorporated an ecological modernization approach with experiential learning to assist participants in achieving this goal. In what follows, the theoretical perspective and pedagogical approach are presented and the PD is described in detail. Analysis of data collected throughout the PD is presented to emphasize the impact of the PD on participants' understanding of energy production processes and their ability to critically analyze various sources of energy. Emphasis is given to the nature of the experiential learning design and its potential to develop environmental literacy.

(C) 2019 by the authors; licensee Modestum Ltd., UK. This article is an open access article distributed under the terms and conditions of the Creative Commons Attribution License (http://creativecommons.org/licenses/by/4.0/). \markb@dbu.edu (*Correspondence) s.quebec.fuentes@tcu.edu 


\section{Contribution of this paper to the literature}

- The professional development (PD) offers a model of a partnership of mathematics and science instruction to guide learners towards environmental literacy regarding energy.

- A detailed description of the PD that incorporated an expanded form of experiential learning to explore the sustainability of diverse energy sources is provided.

- The findings show how the PD utilized the initial stages of mathematical modeling as a way of reflecting on the experiences of the PD to aid participants in gaining a fuller understanding of costs and benefits of diverse energy sources.

\section{ENVIRONMENTAL EDUCATION FOR TEACHERS}

Four overarching critical features of environmental education (EE) for teachers have been identified (Bodzin, Klein, \& Weaver, 2010). Following the recommendations of national science education standards documents (National Research Council, 2000), EE for practicing teachers should include inquiry-based instruction. The North American Association for Environmental Education (NAAEE) emphasizes the importance of inquiry-based instruction in providing learners the opportunity to "construct their own understanding through hands-on, mindson investigations" and to "provide real-world contexts and issues from which concepts and skills can be learned" (NAAEE, 2004, p. 1). When teachers are immersed in such inquiry learning experiences, their own conceptions of the science content improve, they gain a better understanding of how their students learn the content, and their ability to employ inquiry-based instructional methods with their students develops (Loucks-Horsley, Stiles, Mundry, Love, \& Hewson, 2010).

The second critical feature of EE is that it is not limited to developing science content knowledge, but rather includes myriad process skills such as problem-solving, literacy, reasoning, and communication skills (Bodzin et al., 2010), which span multiple academic disciplines (e.g., NCTM, 2000; NGSS Lead States, 2013). Carter and Simmons (2010) emphasize this quality of EE, indicating that EE content derives from "science, mathematics, language arts, social science, politics, and philosophy" (p. 12). Environmental literacy implies a combination of the content knowledge and process skills across these disciplines.

Further, EE should provide learners an opportunity to engage in the content in outdoor spaces (Bodzin et al., 2010). Enacting learning experiences, including professional development, in outdoor spaces allows the learning to be "more authentic, relevant, and meaningful" (Berlin, 2014, p. 107) and encourages learners to take action regarding environmental issues (Bloom, Holden, Sawey, \& Weinburgh, 2010). Engaging teachers in outdoor learning experiences is especially important as doing so models how to guide such instruction so that they may be better prepared to offer similar opportunities to their students (Rebar \& Enochs, 2010). Grounding EE instruction in local outdoor spaces allows the learner to "understand and forge connections with the environment," which provide the "knowledge and skills that help them make sound decisions" (Carter \& Simmons, 2010, p. 13).

Lastly, quality EE instruction for teachers must be a collaborative endeavor (Bodzin et al., 2010). The design and implementation of EE professional development experiences necessitates the collaboration between multiple stakeholders. Winther, Cleary Sadler, and Saunders (2010) describe how authentic EE instruction may not result in learners reaching consensus on an environmental issue, but rather emphasize how distinct values and perspectives can influence individuals' conclusions on such issues.

The PD described herein reflected these four critical components of EE for teachers. In addition, the PD integrated the theory of ecological modernization and the pedagogy of experiential learning.

\section{Theoretical Perspective}

In 1962, Rachael Carson's Silent Spring brought national attention to the potential threats that human activity can pose to the environment. In the decades following, concern for the environment began to take on political undertones as the looming environmental threats began to extend beyond agricultural pesticides, to include industrial manufacturing (CFCs threatening the ozone), urban development (habitat encroachment leading to species decline), and energy production (greenhouse gases contributing to climate change) (Saylan \& Blumstein, 2011). By the beginning of the Reagan administration in the 1980s, environmentalism had become a partisan issue (Friedman, 2008) that presented an apparent need for one to adopt either an ecocentric perspective (and the associated desire to protect the environment) or a technocentric perspective (promoting development and growth) (Bybee, McCrae, \& Laurie, 2009). In such a dichotomy, feuding factions turn to simplified representations of complex environmental issues to promote opposing positions, even though such simplifications fail to represent 
the true complexity (Baimbridge, 2004). Such one-sided representations of issues, along with their politicization, can result in paralyzing indecision about what should be done to remedy them (Saylan \& Blumstein, 2011).

With the aforementioned opposing perspectives of environmental issues being accepted as credible, especially within the current political landscape, educators have an important task of fostering critical thinking skills amongst their students so they can develop informed viewpoints (Slattery, 2015). One perspective educators can adopt to help navigate such political polarization is that of ecological modernization, which contends that protecting the environment does not have to come at the expense of energy development or economic growth (Garner, 2004). Instead, ecological modernization emphasizes that growth can be accomplished in a way that is sustainable, ecologically-friendly, and environmentally conscious.

The PD described in the present paper was based upon the ecological modernization perspective and the premise that all forms of energy have positive and negative impacts to society and the environment - in short, energy production and consumption is complex and there is no single simple answer to energy needs. To make good judgments about complex issues, citizens must first recognize the various stakeholders and the myriad variables that inform their viewpoints (Parker, Wade, \& Atkinson, 2004). However, the preconceived notions and background knowledge that one brings to any experience can influence what evidence one accepts as factual and how one interprets the phenomenon; in short, citizens are prone to see what they expect to see and disregard that which does not fit their expectations (Lederman \& Abd-El-Khalick, 1998). The approach used in the PD was designed to expose learners to these variables in a way that they could actually recognize them and thoughtfully consider their impacts.

\section{Pedagogical Approach}

The pedagogical approach for the PD involved experiential learning enhanced with the initial stages of mathematical modeling. Experiential learning is "the process whereby knowledge is created through the transformation of experience" (Kolb, 1984, p. 38). Kolb describes the process of experiential learning as cyclical, with four phases: concrete experience, reflective observation, abstract conceptualization, and active experimentation. The cycle begins with a concrete experience followed by reflection on that experience. Learners then integrate the experience, prior knowledge, and new knowledge grounding the experience, leading to additional actions. Reflection is critical to experiential learning (Boud, Keogh, \& Walker, 1985), and reflective activities need to be purposefully designed and implemented to foster learning from an experience (FEU, 1981). Mathematical modeling is an example of such a reflective activity.

Mathematical modeling "is the process of choosing and using appropriate mathematics and statistics to analyze empirical situations, to understand them better, and to improve decisions" (NGA \& CCSSO, 2010, p. 72). The Next Generation Science Standards recommends the incorporation of mathematical modeling into science instruction (NGSS Lead States, 2013). Like experiential learning, mathematical modeling is an iterative process, which involves multiple stages: identifying a real-world problem, making assumptions, ascertaining pertinent variables, collecting and analyzing data, formulating a model, implementing the model to find a solution to the problem, evaluating the model and the solution in the context of the original situation, and, if necessary, refining the model based on the evaluation (NGA \& CCSSO, 2010; Munakata, 2006; Pollak, 2011).

The initial stages of the modeling process (i.e., identifying a real-world problem, making assumptions, ascertaining pertinent variables) involve considerable investigation through readings, communication, experience, media, experiments, and experts (Haines, Galbraith, Blum, \& Khan, 2007). Similarly, the literature on experiential learning describes various types of "experiences" (Moon, 1999). For example, Boud et al. (1985) extends the concept of experience beyond on-site visits to include PD sessions, presentations, published research, and unexpected events. Further, Moon explains that experience often involves multiple facets (i.e., on-site visits and expert presentations).

Galbraith, Stillman, and Brown (2010) describe two instructional objectives for incorporating modeling. Modeling as content focuses on implementing the entire modeling process to address an inquiry. Alternately, modeling as vehicle emphasizes the learning of particular content and/or practices associated with the modeling process. For instance, the initial stages of the modeling process, the focus of the PD presented herein, involve determining connections between variables and discerning important information to be included in the model (Blum \& Kaiser, 1991 as cited in Maaß, 2006).

Experiential learning and mathematical modeling are mutually reinforcing processes as can be evidenced by the intersections between their two cycles. As an example, the concrete experience supports the initial phases of the modeling process and the initial phases of the modeling process provide the opportunity to reflect on the concrete experiences. Experiential learning and mathematical modeling are particularly relevant for challenging subjective perspectives and enhancing environmental literacy. Engagement with mathematical modeling allows learners to explore and address societal problems, such as energy production (Blum \& Niss, 1989). When one experiences a 
phenomenon, rather than relying on secondhand information, false subjective beliefs are likely dispelled and more accurate conceptions can form:

\begin{abstract}
False subjective beliefs can often be supported by increased access to information but they are rarely supported by increased access to experiences. The more we actually experience things and use the information available to supplement and complement our knowledge, the greater and more accurate the understanding. (Garvey, 2013, para. 6)
\end{abstract}

The experience not only requires interaction with the environment but also communication with others and receptiveness to novel understandings and various stances (Medrick, 2013). The learner is engaged on multiple levels (e.g., intellectual, emotional, social, political, spiritual, and physical) and, through such engagement, becomes an informed and involved citizen (Blum \& Niss, 1989; Itin, 1999).

\title{
Purpose
}

The purpose of the present paper is to describe the implementation and outcomes of a PD designed to encourage inservice science teachers to evaluate six prominent local energy sources. Specifically, the participants engaged in experiential learning to navigate the contentious political landscape and to consider the environmental impacts of each energy source. The researchers addressed the following:

1. How does a PD utilizing experiential learning impact inservice science teachers' conceptions of energy production and its environmental implications?

2. How do the teachers perceive their growth resulting from engagement in such PD?

\section{METHODS}

\section{Participants and Setting}

Sixteen inservice science teachers (nine females and seven males) participated in the PD. Nine participants taught middle school science and seven taught at the high school level. Four participants were African American, two were Latin@, one was Asian, and the remaining nine were white. Seven participants were traditionally certified while nine had earned alternative certification - all did not meet the State standard of 'highly qualified' for their content specialization. Among the seven secondary science teachers, one taught biology and environmental systems, one taught chemistry, and five taught biology. All but two of the participants taught in the same large, urban school district.

The PD spanned three weeks during the summer followed by once monthly sessions during the academic year and took place on campus at a private university in the Southwest United States. Instruction was led both in the classroom setting as well as on various field trips to energy production/extraction sites across the state. The PD providers included a science educator (first author), a mathematics educator (second author), and a professional geologist (also a doctoral candidate in the science education program). All but one of the participants had previously engaged in professional development activities with the PD providers (nine had two years prior experience and six had one year prior experience).

\section{Professional Development Program Description}

To learn about the production process and implications of six distinct energy sources, participants toured energy extraction sites, production sites, and one museum. Emphasizing the ecological modernization approach, the PD providers exposed the participants to the myriad concerns regarding each energy source. Perspectives were provided by energy sector representatives, wildlife biologists, environmental geologists, television (news), radio (podcasts), and films (mainstream and documentary) (Table 1). After considering divergent views on each energy source, participants engaged in the initial stage of the mathematical modeling process to evaluate each energy source regarding its environmental costs and benefits. Group presentations and discussion allowed the participants to further evaluate the energy sources and to consider the environmental politics regarding them.

Part 1 - Introduction to mathematical modeling. After initial introductions of PD participants (providers and teachers) and an overview of the overarching purpose of the PD, the mathematics educator began instruction by conducting two sessions focused on developing participants' understandings of the mathematical modeling process. The initial activity tasked the participants to identify variables that must be considered when addressing a problem, one of the initial steps in the modeling process. Specifically, they were asked to generate a list of variables, a feature list (Moscardini, 1989), that they must consider in order to determine the appropriate time to leave their home to ensure they arrive at work on time. Participants were encouraged to discern variables that 
Table 1. Energy Sources, Location of Instruction, and Representations of Energy Sources

\begin{tabular}{|c|c|c|}
\hline Energy Source & Location of Event & Representations of Energy Source \\
\hline Oil & - History of Oil Museum & $\begin{array}{l}\text { - Video and tour by museum representative } \\
\text { - Video - A Crude Awakening: The Oil Crash } \\
\text { - News - Deepwater Horizon oil spill in Gulf of Mexico }\end{array}$ \\
\hline Coal & $\begin{array}{l}\text { - } \quad \text { Coal Stripmine } \\
\text { - } \quad \text { Coal Powered Electric Power Plant }\end{array}$ & $\begin{array}{l}\text { - Tour of mine and power plant by energy company representatives } \\
\text { - Video - Burning the Future: Coal in America } \\
\text { - Video - Coal Country }\end{array}$ \\
\hline Wind & - Wind Farm & $\begin{array}{l}\text { - Wind energy representative presentation } \\
\text { - Research ecologist presentation }\end{array}$ \\
\hline Nuclear & - Nuclear Power Plant & $\begin{array}{l}\text { - Video and tour by power plant representatives } \\
\text { - Video - Silkwood } \\
\text { - News - Fukushima Daiichi nuclear power plant meltdown }\end{array}$ \\
\hline Hydroelectric & - Hydroelectric Dam & $\begin{array}{l}\text { - } \text { River Authority representative presentation and tour of dam } \\
\text { - Video - Deliverance } \\
\text { - News - 2010/2011 Texas drought } \\
\end{array}$ \\
\hline Natural Gas & - Classroom & $\begin{array}{l}\text { - Natural gas energy representative presentation } \\
\text { - Video - Gasland }\end{array}$ \\
\hline
\end{tabular}

would likely influence their arrival time (e.g., traffic lights and speed limit) from variables that would have negligible effect (e.g., wind resistance and weight of gas in fuel tank). To understand how the feature list they had created fit into the modeling process, the participants were introduced to the purpose of modeling and were challenged to identify the stages in developing a model. Finally, in groups, participants began creating a model to address the problem: "What is the cost to the environment of buying produce grown locally versus not locally?" To close the second modeling session, groups shared drafts of the models they had created. Although they did not master the skill of developing a model, the modeling as vehicle approach had guided participants to think more broadly about potential variables that could relate to a problem. With this background knowledge on the modeling process the participants were now prepared to continue into the second portion of the PD.

Part 2 - Exploring various energy sources. With a focus on identifying pertinent variables related to the environmental costs of energy production, participants engaged in experiential learning about six distinct energy sources. To prepare for studying each energy source, participants read a corresponding chapter from The Energy Report (Texas Comptroller of Public Accounts, 2008). Each chapter detailed the annual production/extraction and use of each energy source across the State of Texas. The Energy Report presented statistics about each energy source in an apolitical and nonbiased manner. After reviewing the status of each energy source, when possible, participants were taken to onsite locations to allow them to observe extraction, production, and/or use firsthand. Participants were able to tour facilities that were actively producing electricity via coal, wind, nuclear, and hydroelectric power. Participants learned about natural gas and oil through guest presentations in the classroom. Two energy sources, coal and hydroelectric, will be described in greater detail in what follows.

Prior to touring the coal mine, participants viewed the documentary film Coal Country (Geller \& Evans, 2009). This film portrayed the process of mountaintop removal coal mining in West Virginia and the human health and environmental costs of the practice. However, it also revealed the significant economic dependence that local communities have on the coal industry. After gaining some insight into coal energy (extraction and production) participants toured the Oak Hill Mine in Henderson, Texas, led by an energy company representative. At this site, participants saw the widespread defoliation and surface destruction, characteristic of strip mining extraction; a process quite distinct from what was portrayed in the documentary. While touring the site, the energy representative also showed participants a reclaimed area (post-extraction) where the company had replanted trees, impounded water into a small pond, and restored the environment sufficiently for wildlife to return. After touring the strip-mine, participants took a short bus trip (approximately 20 minutes) to the primary consumer of the coal extracted at Oak Hill, namely the Martin Creek Steam Electric Power Plant, where their tour continued. In contrast to the natural beauty of the reclaimed strip-mining operation they had just left, at Martin Creek, participants were confronted with the industrial facility that burned the coal to generate energy and witnessed the emissions firsthand that were discharging into the air above. After touring the plant, participants watched another coal documentary, Burning the Future: Coal in America (Novack, Rosenfeld, Follini, \& Zoullas, 2008). This film also documented the negative effects to citizens' health, groundwater purity, and wildlife habitat. It also depicted the coal industry as a powerful force contributing to environmental degradation and loss of the West Virginians' way of life.

The last field experience in which participants engaged was related to hydroelectric power. Participants traveled to Buchanan Lake in Burnett, Texas where they stayed overnight in the Lower Colorado River Authority (LCRA) housing directly adjacent to the hydroelectric dam. The lodging location allowed participants to enjoy what they perceived to be the natural beauty of the lake, including the wildlife (e.g., bats, insects, birds) that inhabited 
the region. The following day, under the guidance of an LCRA employee, participants toured the interior structure of the hydroelectric dam. Throughout the tour, participants learned about the benefits and limitations of hydroelectric power generation, particularly regarding the impact of drought on production capabilities. This was particularly relevant due to the ongoing drought throughout Texas at the time of the PD. After touring the dam, to bring to light the environmental impacts of hydroelectric power production, participants watched the film Deliverance (Boorman, 1972). This film depicts the impoundment of a river in rural Appalachia and the consequences of such ecosystem alteration to wildlife habitats and human residences.

Part 3 - Synthesizing activities. After exploring all six energy sources, participants were asked to create a mathematical model that could be used to evaluate the environmental costs, benefits, and impacts of each. Participants were divided into groups to develop their models. Using the modeling as vehicle approach, the intention was not for participants to finalize a model, but rather to help them recognize the complexity of making such a determination in light of the myriad variables that must be considered.

After considering the multitude of variables related to the environmental impacts of energy production by engaging in the initial stages of the modeling process, the participants were ready for the final activity of the PD. Each group was assigned one source of energy and was told to adopt a position either for or against its use. PD providers determined which position groups would take that would counter the general perspectives (usually stereotypical) held by the group. For example, since hydroelectric power generation is generally viewed as an ecologically friendly practice, one group was instructed to present the negative aspects of this power source. Later, when the presentations were delivered to the rest of the participants, the audience was instructed to challenge the position of the presenters. This closing activity aligned with the overarching purpose of the PD, to highlight the complexity of each energy source and to demonstrate that simplistic views of energy production are, by default, one-sided and insufficient.

\section{Data Sources and Analyses}

At the outset of the PD, participants completed a pre-assessment to document their basic understanding of energy production processes and environmental impacts. Particularly, the participants answered the following two prompts:

- Describe [energy source] and tell how [energy source] is used to generate power.

- What are the environmental costs to [energy source] generated power?

Participants answered these questions for each energy source included in the PD. This assessment was also administered at the completion of the PD. Inductive coding (Thomas, 2006) was utilized to analyze the responses to each prompt. As the researchers read through the responses, distinct elements of the answers were identified and compiled into a list representing the groups' understanding of the production process for each energy source (prompt 1) or their corresponding environmental costs (prompt 2). To determine the participants' relative understanding of each energy source, the number of distinct elements found within their answer was compared to the aggregate list generated by the group. The inductive coding process was repeated for the post-assessment to determine growth in understanding (via additional identified distinct elements) for both the group and each individual.

Participants also responded to 11 survey questions about the PD distributed throughout the course of the PD. These questions were administered twice during the summer session (S1 and S2) as well as six times during the academic year following (AY1-AY6). All questions were administered through the online tool Zoomerang ${ }^{\odot}$. S2, AY1, AY2, AY4, and AY6 administrations had only one open-ended prompt to which the participants replied, whereas S1, AY3, and AY5 each had two prompts (Q1 and Q2). The questions focused on the participants' perspectives about how the PD influenced their content knowledge (e.g., How did the PD experience expand your depth of understanding of the concepts related to your area of teaching?), their classroom practices (e.g., How are you planning to implement the ideas from the PD?), and their thinking about teaching and learning (e.g., How did the PD impact your thinking about teaching and learning?). Together, the researchers analyzed the responses using the constant comparative method (Glaser \& Strauss, 1967). The coding process consisted of two distinct stages. The first round of analysis resulted in an initial list of codes. The second stage of the analysis involved re-coding the data using the generated list of codes. This process resulted in the merging of some codes as well as elimination of others. For example, conceptual change and reconsidering ideas were merged into one code, namely conceptual change. Finally, the codes were organized into three themes: energy and society, knowledge gains, and PD to the classroom. The themes, and the codes that fall within each, are presented in the findings. 
Table 2. Distinct Elements of Description and Number of Environmental Costs of Each Energy Source Identified by Participants on the Pre- and Post-Assessments

\begin{tabular}{lcccc}
\hline \multirow{2}{*}{ Energy Source } & \multicolumn{2}{c}{ Description } & \multicolumn{2}{c}{ Environmental Costs } \\
\cline { 2 - 5 } & Pre-Assessment & Pre- and Post-Assessment & Pre-Assessment & Pre- and Post- Assessment \\
\hline Coal & 6 & 6 & 8 & 10 \\
\hline Hydroelectric & 3 & 3 & 5 & 8 \\
\hline Natural Gas & 4 & 5 & 10 & 12 \\
\hline Nuclear & 5 & 5 & 9 & 10 \\
\hline Oil & 5 & 6 & 7 & 13 \\
\hline Wind & 2 & 3 & 7 & 10 \\
\hline
\end{tabular}

\section{FINDINGS}

Ten of the 17 participants completed both pre- and post-assessments. Participants' responses to the first question on the assessment gave insight into their understandings of how energy was produced through the various sources. The second column of Table 2 represents the count of distinct elements of an informed understanding of energy production that were identified among all the pre-assessments for each energy source. The third column represents the total number identified among the pre- and post-assessments. For example, in the pre-assessment of their understanding of nuclear power, the participants identified five distinct elements: 1) radioisotope materials used, 2) steam is generated, 3) steam turns a turbine, 4) generator transforms energy, and 5) mining for fuel. No additional elements were identified in the post-assessment. The same result occurred for hydroelectric and coal energy. However, with natural gas, oil, and wind power, one additional element was identified in the post-assessment.

With regard to environmental costs of energy production, however, the group's understandings demonstrated more growth between pre- and post-assessment. For each energy source, additional environmental costs were identified in the post-assessment. For example, on the pre-assessment wind energy environmental costs item, the participants identified 1) bird mortality, 2) bat mortality, 3) vegetation impact, 4) space required, 5) noise pollution, 6) energy cost for construction, and 7) pollution during manufacturing process. Three additional environmental costs were identified in the post-assessment: 8) restrictions to land use, 9) aesthetics, and 10) unspecified wildlife impacts. The number of additional environmental costs identified through the post-assessment ranged from one to six; columns four and five of Table 2 present this growth.

While Table 2 depicts changes that occurred within the entire group during the span of the PD, it fails to show individual growth among participants. In the subsequent section, individual gains in both understandings of energy production methods and their environmental costs are presented for coal and hydroelectric power. These two energy sources are chosen because one (hydroelectric) is generally considered to be a more environmentally friendly energy production method while the other (coal) is generally considered to be more harmful to the environment.

\section{Findings for Coal}

The findings for coal power are displayed in Table 3. Regarding how coal is used to generate power, in the preassessment participants identified six distinct elements of an understanding of coal generated power: 1) coal mined from earth, 2) different grades of coal, 3) coal burned, 4) steam generated by heat, 5) steam turns turbine/generator, and 6) generator converts mechanical energy to electrical. No additional elements were identified on the participants' post-assessment responses. While two of the participants showed no gains after instruction, eight of the 10 participants identified additional elements (ranging from one to three) in their post-assessment responses. As an example, participant eight identified three distinct elements in the pre-assessment:

Fossilized remains of photosynthetic organisms, is burned to generate heat, makes steam to turn generator.

In this response, the participant alluded to the codes 3) coal burned, 4) steam generated by heat, and 5) steam turns turbine/generator. In the post-assessment, participant eight identified four distinct elements, but two of them were not identified in the pre-assessment:

Coal is a naturally occurring mineral hydrocarbon made up of the fossilized remains of vegetation. It is burned to produce heat energy that may be used for heating buildings or making steam which in turn can be used in the form of mechanical energy or converted to electricity. 
Table 3. Distinct Elements of Description and Number of Environmental Costs of Coal Energy on the Pre- and Post-Assessments for Each Participant

\begin{tabular}{|c|c|c|c|c|}
\hline \multirow[b]{2}{*}{ Participant } & \multicolumn{2}{|c|}{ Description } & \multicolumn{2}{|c|}{ Environmental Costs } \\
\hline & Pre-Assessment (out of 6) & $\begin{array}{c}\text { Pre- and Post-Assessment } \\
\text { (out of 6) }\end{array}$ & Pre-Assessment (out of 8 ) & $\begin{array}{c}\text { Pre- and Post-Assessment } \\
\text { (out of 10) }\end{array}$ \\
\hline 1 & 3 & 5 & 3 & 5 \\
\hline 2 & 3 & 3 & 4 & 5 \\
\hline 3 & 2 & 4 & 3 & 5 \\
\hline 4 & 5 & 5 & 3 & 5 \\
\hline 5 & 1 & 3 & 4 & 5 \\
\hline 6 & 4 & 5 & 4 & 6 \\
\hline 7 & 0 & 1 & 2 & 3 \\
\hline 8 & 3 & 5 & 2 & 2 \\
\hline 9 & 4 & 5 & 2 & 4 \\
\hline 10 & 1 & 4 & 0 & 2 \\
\hline
\end{tabular}

In this response, participant eight alluded to five codes. Three codes were seen in the pre-assessment response: 3) coal burned, 4) steam generated by heat, and 5) steam turns turbine/generator. Two new elements of coal power production were identified in the post-assessment: 1) coal mined from earth and 6) generator converts mechanical energy to electrical. In addition to the increased knowledge of coal power, in the post-assessment response, participant eight also demonstrated an ability to better articulate her understanding of coal power.

Regarding the environmental costs of coal generated power, in the pre-assessment, participants identified eight distinct environmental costs: 1) non-renewable, 2) landscape degradation, 3) wildlife impact, 4) greenhouse gas emissions, 5) other emissions, 6) water pollution, 7) human health impacts, and 8) general pollution. In the postassessment, two additional environmental costs were identified: 9) water usage and 10) emissions from equipment. In the pre-assessment, individual participants identified four or less of the 10 environmental costs. Nine of the participants, however, identified one or two additional environmental costs in their post-assessment responses. As an example, participant nine identified two environmental costs in his pre-assessment:

\section{Coal requires mining, including strip mining to get the coal out of the ground. Coal burning releases air pollution which requires filters to control.}

In this response, participant nine alludes to 2) landscape degradation and 5) other emissions. In his postassessment response, he identified two additional environmental costs:

\section{Burning coal produces several pollutants including ash, nitrous oxides, sulfur, mercury. All of these have some negative impact on humans and other living organisms. Most of them have a negative financial impact as well in the form of illness, etc.}

Here participant nine has also alluded to 3) wildlife impact and 7) human health impacts. Similar to participant eight's post-assessment response, this also shows a better ability to communicate his understanding of the environmental costs of coal power than was observed in the pre-assessment.

\section{Findings for Hydroelectric}

The findings for hydroelectric power are found in Table 4. Regarding how hydroelectric power is generated, in the pre-assessment, participants identified three distinct elements: 1) dam impounds water, 2) water turns turbine, and 3) generator. No additional elements were identified by the participants' post-assessment responses. While two of the participants showed no gains after instruction, seven of the 10 participants identified one additional element in their post-assessment responses, and one participant identified all three elements for the first time in his postassessment. As an example, participant four identified only one element in the pre-assessment:

Water with help of gravity falls, spins turbine, generates electricity.

In this response, the participant alluded to the code 2) turbine, but failed to include 1) dam impounds water or 3) generator converts mechanical to electrical. In the post-assessment, participant four identified an additional element:

Water is dammed and stored. It is then released through pipes that spin a turbine. Electricity produced by turbine is sent to power company through electric wires and then to homes, businesses, etc. 
Table 4. Distinct Elements of Description and Number of Environmental Costs of Hydroelectric Energy on the Pre- and PostAssessments for Each Participant

\begin{tabular}{|c|c|c|c|c|}
\hline \multirow[b]{2}{*}{ Participant } & \multicolumn{2}{|c|}{ Description } & \multicolumn{2}{|c|}{ Environmental Costs } \\
\hline & Pre-Assessment (out of $\mathbf{3}$ ) & $\begin{array}{c}\text { Pre- and Post-Assessment } \\
\text { (out of } 3 \text { ) }\end{array}$ & Pre-Assessment (out of 5) & $\begin{array}{c}\text { Pre- and Post-Assessment } \\
\text { (out of } 8 \text { ) }\end{array}$ \\
\hline 1 & 2 & 3 & 1 & 4 \\
\hline 2 & 2 & 2 & 3 & 5 \\
\hline 3 & 1 & 2 & 2 & 3 \\
\hline 4 & 1 & 2 & 1 & 2 \\
\hline 5 & 1 & 2 & 1 & 3 \\
\hline 6 & 2 & 3 & 1 & 4 \\
\hline 7 & 0 & 0 & 0 & 0 \\
\hline 8 & 2 & 3 & 2 & 4 \\
\hline 9 & 2 & 3 & 2 & 2 \\
\hline 10 & 0 & 3 & 0 & 0 \\
\hline
\end{tabular}

In this response, participant four alluded to two codes: 1) dam impounds water and 2) turbine spins. Like the example given for coal power, participant four also demonstrated an ability to better articulate her understanding of how hydroelectric power is generated.

Regarding the environmental costs of hydroelectric power, in the pre-assessment participants identified five distinct environmental costs: 1) dam floods existing habitat, 2) reduced water downstream for wildlife, 3) sediment build-up behind dam, 4) disrupts fish migration, and 5) construction pollution. In the post-assessment, three additional environmental costs were identified: 6) disrupts water supply for humans, 7) aesthetics, and 8) greenhouse gasses from decaying material. In the pre-assessment, individual participants identified three or less of the environmental costs with the majority of participants identifying two or less. Seven of the participants, however, identified between one and three additional environmental costs in their post-assessment responses. As an example, participant six identified only one environmental costs in his pre-assessment:

Destruction of large area for reservoir created by dam = loss of biodiversity/change in ecosystem.

In this response, participant six alludes to the code 2) water covers existing ecosystem. In his post-assessment response, he identified three additional environmental costs:

\section{Habitat destruction/altered landscape, people displace, $\mathrm{H} 2 \mathrm{O}$ use impacts downstream, sediment build- up $=$ greenhouse gases.}

Here participant six has also alluded to the codes 1) dam floods existing habitat, 2) reduced water downstream for wildlife, 3) sediment build-up behind dam, and 8) greenhouse gases from decaying material.

\section{PD Survey Findings}

During and over the nine months following the three week PD, participants completed a series of additional surveys to evaluate the experience and describe its impact on them as educators. The analysis of this survey data revealed how the participants were impacted by the PD and what characteristics of the PD they felt were responsible for this change. The pre- and post-assessment showed content knowledge growth among the participants regarding both production methods and environmental costs. The PD evaluation survey revealed three themes regarding other impacts of the PD: energy and society, knowledge gains, and PD to the classroom. Table 5 contains the codes that fell within these themes as well as the count of how many times each code was identified during data analysis.

Many participants indicated that visiting actual energy sites helped them understand how energy intersected with their actual lives and contributed to their ability to make more informed choices about energy. The participants reported how their perspectives on energy were challenged and their knowledge was expanded by the exposure to the diverse stakeholders and their views. Participants further described their desire to infuse characteristics from the PD into their own instruction to ensure their students would recognize the complexity of energy production and develop deeper understanding to help them become informed citizens.

Energy and society. The first theme involved the participants' perspectives on the importance of how the PD connected the topic of energy to society. The five codes within this theme (power of experiential learning, ecofriendliness, recognizing agendas, real-world connections, and informed citizenry) reflect a variety of perspectives ranging from the general impact of on-site experiential learning as well as how the approach helped foster a mindset of eco-friendliness, to recognizing how competing agendas present energy in distinctively different lights, to the 
Table 5. Codes and Counts Organized by Themes

\begin{tabular}{|c|c|c|}
\hline Theme & Code & Count \\
\hline \multirow{5}{*}{ Energy and society } & Power of experiential learning & 15 \\
\hline & Eco-friendliness & 6 \\
\hline & Recognizing agendas & 22 \\
\hline & Real-world connections & 18 \\
\hline & Informed citizenry & 6 \\
\hline \multirow{5}{*}{ Knowledge gains } & General & 9 \\
\hline & Misconceptions & 3 \\
\hline & Energy & 14 \\
\hline & Complexity of energy & 13 \\
\hline & Conceptual change & 11 \\
\hline \multirow{6}{*}{ PD to the classroom } & General & 6 \\
\hline & Activity & 17 \\
\hline & Content & 29 \\
\hline & Pedagogy & 28 \\
\hline & Vicarious experiential learning & 12 \\
\hline & Transformative & 18 \\
\hline
\end{tabular}

impact of energy production and consumption on the real world. The fifth code, informed citizenry, addresses how energy literacy is important for individuals to make informed choices regarding energy policy and consumption.

A number of participants emphasized how being on-site and experiencing the energy production sites had a tremendous impact on their learning: "The on-site trips and learning opportunities provided me with information and ideas that I don't think I would have been able to experience from a book or researching the ideas on my own" (P1, AY3-Q2). Some specifically indicated how the on-site experiences impacted them:

The trips to the Oak Hills Mine and Lake Buchanan Dam were probably the most impressive to me. Both times I was impressed at the size of the mine and the dam. It caused me to think about how much land area is needed to produce the power we need. $(\mathrm{P9}, \mathrm{S2})$

Many participants acknowledged that experiencing energy production in the environment led to the development of an enhanced sense of ecological concern; one described how it impacted her own eco-friendliness and how this extended to her family as well: "However, the experiences from this summer and further learning during the academic year have allowed me to think about energy in a new way and has influenced choices my family has made about energy consumption" (P10, AY5-Q2).

While developing eco-friendliness is a positive outcome, a more impressive goal was realized in participants who began to recognize how different interest groups, with competing agendas, could represent energy production/consumption from drastically different perspectives. One participant indicated a realization that she had accepted representations of energy without questioning their truth: "What I realized during the 3 week [PD] this year is that I had ideas about energy sources that had no real basis other than what I've heard from groups that are on an extreme end either for or against" (P4, AY1). Another recognized how competing agendas might each have their own elements of truth and bias:

The most significant theme that I picked up on, throughout the summer professional development, is that with each person we met we heard a different view point of the same story and that each view point each has its strengths and weaknesses and many times the varying opinion, facts, and general information contradict each other. (P8, S2)

Participants indicated that the real-world connections made during the PD instruction was instrumental to the positive outcomes they perceived,

Not only did the speakers and site visits make the content more relevant, but it also connected us to what was happening here in our community, in our place. This is an aspect of place-based education that I really had not explored directly in teaching, or in learning. (P1, AY1-Q1)

Others related how they recognized the importance of the real-world connections made during the PD by sharing how they were striving to do the same with their science teaching:

I've made more of an effort to help [students] understand the importance of what we are studying and how it relates to their lives. I attribute some of my change in approach to this [PD] program, from the 
first summer I attended, has always made attempts to show the relevance in what we were doing. (P4, AY5, Q2)

The participants also communicated how the PD helped them recognize the importance of energy literacy for their students to help them develop into into informed citizens: "The more my students know about energy, the better informed consumers they will be. It is important to introduce and then expand the amount of knowledge concerning my students' need to deal with energy issues in their future" (P3, AY1). Another emphasized how developing the ability to think independently and critically evaluate information would be useful for all students, "I want all of my students to become independent thinkers and productive members of society regardless of what profession they might choose" (P13, AY3-Q2). Through these codes, related to energy and society, the participants of the PD articulated a number of ways that the nature of the PD instruction, namely experiential learning and connecting the content to the real-world, had positively impacted them and their instruction by fostering ecofriendliness, helping them recognize competing agendas, and developing energy literacy to become informed citizens.

Knowledge gains. The second theme centered on the participants' own content knowledge gains regarding energy production and consumption. The five codes within the theme (general, misconceptions, energy, complexity of energy, and conceptual change) represent a range of perceived knowledge gains from correction of misconceptions about energy, to recognition of the complexity of energy production and consumption, to participants' own conceptual change.

A number of participants reflected on their positive feeling regarding the PD's effect on their general content knowledge: "I was fortunate enough to acquire so much knowledge and resources this past summer" (P16, AY2Q2). Others, specifically referenced how the PD experience helped grow their knowledge by remediating misconceptions: “As I stated in class, I only got so much out of my undergrad and discussing the concepts of energy really helped flesh out some misunderstandings I had" (P15, AY3-Q2). Another participant indicated that prior to the PD, his basic understanding of energy was quite limited and that the PD had helped his understanding develop:

We had a physics professor come in and demystify the "magic" of how lights came on. While for someone who studies electrical transmission, generation and transportation everyday may have viewed the lesson as menial and simple, I thought the information was amazing. (P6, AY1)

An extension of learning more about energy, some participants were impressed by the complexity of energy issues:

But, what I'm really taking home with me is the ability to understand that there is no one answer to our energy problems. We've really evaluated these different energy sources for what they are, both good and bad, and been able to more balance our ideas of where our energy in the United States should come from. (P3, S2).

Perhaps the most noteworthy knowledge gains among the participants were those that led to personal conceptual change (i.e. reconsideration of preconceived notions about energy). One participant clearly explained how the PD had caused her to reconsider many preconceived notions about energy and how she left the experience with a new way of thinking about energy in all its forms:

I learned that hydropower is not necessarily an important source of energy as it is a source of water
supply. Not many dams are being built and the ones (or the one in East Texas) is being built not for
providing energy but providing needed water for inhabitants. I also learned that the disadvantages of
windpower are quite true. Maybe the old ones made a lot of noise, but the ones I actually saw were
quiet, not even a whisper. And they don't kill thousands of birds, but bats. But measures and research
are being done to prevent that. I also saw with my own eyes a nuclear plant up close and the building
that houses the waste- on the same property! There is an existing problem of where to house radioactive
waste. Who wants it in their backyard? Not me! I also got to see a coal mining site and the plant that
uses the coal for energy Pretty awesome. I was impressed that steps are being taken to reclaim the land,
albeit not quite the same. The coal plant itself left me a little unnerved. The waste water lake and the
land being used is not environmentally healthy. (P2, AY5-Q2)

In this single statement, the participant emphasizes how she views hydroelectric, wind, nuclear, and coal power in a new, more informed, light. She clearly indicated that being able to personally witness (visually and audibly) energy production sites had transformed her perceptions of these energy sources and how the experience had also evoked a visceral response in her that contributed to her learning experience.

PD to the classroom. The final theme pertains to aspects of the PD that the participants deemed to have an influence on their practice. The six codes within the theme (general, activity, content, pedagogy, vicarious 
experiential learning, and transformative) reflect a range from general comments to more specific references to activities conducted, content addressed, and pedagogical approaches utilized during the PD. The final code, transformative, represents a philosophical change in how the participants thought about teaching science.

Several participants provided overarching descriptions about how the PD offered direct benefits for their science instruction: "This program provides real data and material that is immediately usable in the classroom" (P4, S1-Q1). However, the majority of the participant reflections elaborated about specific aspects of the PD that had an impact on their practice. For instance, participants identified activities incorporated into the PD that they planned to use or already used in their classroom. Many participants acknowledged the building of a model windmill as one of these activities: "I am also going to use the windmill kit with the students to teach variables, fair testing, inquiry, etc. I am going to let them test out blades and try to light a bulb" (P1, S2). Participants also described implementing activities similar to the pro/con synthesizing activity for the PD:

I started by getting my students to research the energy providers in our area and the types of energy that they provide. My students were able to identify the pros and cons of each energy resource. This caused them to also look at the ways the providers were helping or hurting the environment. (P3, AY5Q3)

Individual participants also mentioned reading credible resources and showing films.

The PD experiences also had a profound effect on participants' content knowledge and, in turn, their instruction related to energy: "This year provided a lot of opportunity to explore in depth the concepts of energy production and delivery. This has expanded my content knowledge and improved my delivery in the classroom" (P8, AY3Q2). For one participant, this meant providing information beyond what is presented in the textbook:

When we discuss energy sources, my resource is the textbook, so I can only give my students the advantages/disadvantages that the text provides, which happen to be those notions. Now I can factually give my students info that I personally saw and know, thus providing more info than the text. In addition, we can have better discussions and better presentations from me. Also, I can talk more knowledgably about nuclear, hydropower, and coal plants. (P1, S2)

Another participant realized and reconciled a misconception:

After visiting the Kilgore museum and talking with the speaker from the natural gas company I realized that both oil and natural gas were found in the space between the "rock" particles. This misconception I found was also one my students had and I was able to explain to them what is really happening when the oil or gas is extracted. Again the [PD] was a wealth of information I could use in my classroom. (P11, AY2-Q2)

The participants' enhanced content knowledge helped to make connections for themselves and their students across content areas:

I have become more aware of the interconnectedness of the different sciences. It seems that every time we start to learn more about a concept, we are able to go back to previous concepts and tie them in. This has allowed me to demonstrate to my students how earth sciences, physics, chemistry, and life sciences have connections to each other. (P3, AY2-Q3).

Participants also had increased confidence in teaching the content, as exemplified by one of the participant's comments:

During the summer... I was able to absorb a lot of information from different resources. I realized that I had learned so much in those experiences that I was able to get my classes and teach with confidence and I was able to use all that knowledge I had learned. (P5, AY5-Q2)

Overall, through the array of resources and experiences provided though the PD, participants constructed a robust content knowledge that influenced their instruction.

In addition to developing content knowledge, the PD exposed participants to an array of pedagogical approaches: "I struggle to come up with different viewpoints and ideas, and a lot of the discussion we have had has helped me to diversity my lessons" (P14, S1-Q2). Participants described some of the "pedagogical tools" (P11, AY6) they now incorporate in their practice including hands-on learning, current events, and questioning:

I feel that the most important part of this experience was that it reinforced for me the idea that students need as many hands-on experiences as possible with the content we are teaching them. (P4, AY3-Q3) 
I sometimes use short news articles as a warm up or start of discussion in my class. ... For example, ... I chose an article about a nuclear explosion that happened in Marseille .... We discussed where it was and related to/compared it to other nuclear problems that had occurred in other parts of the world especially the Fukushima accident after the tsunami last year. We ended talking about Earthquakes which was the topic we needed to talk about that week. (P11, AY2-Q2)

In the beginning of teaching, I would sometimes cave to [students'] requests and simply give them the answer. Learning that this is not the best way to develop their skills, I am now able to find new ways to question them so that they ... persevere and find what they are looking for. (P13, AY5-Q2)

Yet, one participant articulated challenges to employing such practices:

The politics of administrators and the bureaucracy of large institutions and the resistance to change and new ideas prevent the implementation of our professional development. Lack of support or resources also make it difficult. With budget cuts and no funding for new programs, teachers are struggling just to continue hands on learning. (P1, S1-Q2)

Established school structures may prohibit, or at a minimum may require creative means for, the integration of the pedagogical approaches presented in the PD.

Experiential learning, which had an impact on the PD participants, is an example of how they adapted a practice to function within the circumstances of their particular setting. One participant intended to incorporate on-site visits: "I plan on giving my students a chance to visit a few sites" (P11, AY5-Q3). However, several participants indicated that such visits are not feasible: "It would be epic of we could find ways to get children ... out in the world, seeing ... real time experiences that we have had here in [the PD]. Clearly this is cost prohibitive" (P3, AY1). Other participants identified alternatives to on-site visits. For instance, participants described the value of expert speakers:

The guest speakers also provided me insight into the value of a guest speaker when a field trip is not possible. I have often found it frustrating that students could not experience environmental science IN THE FIELD and felt the lesson was lost in lecture. THEN we had our natural gas lecturer come in and he had so much insight that I realized there were very viable alternatives. (P6, AY1)

In addition to guest presenters, participants explained other ways that they could convey their experiences to their students. For example, the participants could serve as a resource themselves: "Having experienced the field trips to cold mines, nuclear plant, windfarm, and seeing those first hand and the operations involved allow be to be a live reference for students" (P17, AY5-Q2). Some participants video-taped their experiences:

After this I showed video of the coal mine we visited this summer and interview clips with a mine worker discussing the lengths at which companies are expected to go in order to reclaim areas they have disturbed as a result of their mining. (P14, AY2-Q2)

By conveying their experiences via pictures, video, or first-hand accounts, participants were able to provide their students with vicarious experiential learning opportunities.

For some participants, their experience with the PD led them to reconsider how students learn science. For example, participants identified inquiry as a theme of the PD: "All of the things that we saw this summer were focused through the lens of scientific inquiry. The ... presenters have ... model[ed] ways to present scientific thought to students and I have carried that idea to my own students" (P12, AY2-Q2). This shift in perspective requires a change in both student and teacher actions. Students need "to take information provided to them and evaluate it thoroughly based on the source, and quality of scientific evidence and claims" (469108, AY5-Q3). Another participant described her role to support students in this endeavor:

I try to help them see there is a different mindset. It is possible to open the eyes and ears and see and hear things differently. To question and ponder. These are the things that have helped me to become a better teacher and I feel that my role has been less to answer their questions but to question their answers. (P8, AY2-Q2)

Engagement with the various PD components (activities, content resources, and an array of pedagogical strategies including experiential learning) resulted in a transformation in how some participants thought about the teaching and learning of science. 


\section{DISCUSSION}

The overarching purpose of the PD was to increase participants' content knowledge regarding diverse energy sources, expose them to the environmental and societal costs and benefits of each, and to help them recognize the complexity of energy production and consumption. By framing the PD with the ecological modernization perspective (Garner, 2004), participants were encouraged to recognize the environmental and societal costs and benefits of each energy source. To accomplish this goal, participants' preconceived notions were challenged through experiential learning.

The data overwhelmingly revealed that the participants felt that experiencing the energy production and extraction sites in person (Bodzin et al., 2010) had powerful impacts on them. However, upon closely examining the participants' comments about the PD, the influence is derived by more than just standing under wind turbines or touring a coal power plant. Critical to the PD's effectiveness were the myriad other components that were strategically integrated with the on-site visits. Throughout the data, participants recognized the value of the background literature, presentations from industry and environmental stakeholders (Bodzin et al., 2010), discussions of current events, simulated research, and viewing related media (e.g., documentary films). Adopting this expanded view of what constitutes experiential learning (Boud et al., 1985; Moon, 1999) enhanced the on-site visits by exposing participants to multiple, and often conflicting, perspectives on energy from diverse sources and in diverse forms. Incorporating these multiple elements with the on-site visits made the experience an authentic opportunity to develop deeper understanding of the complexity of energy; however, on their own, they would not be sufficient to accomplish the PD goals.

Reflection is also a critical component of experiential learning (Boud et al., 1985). Mathematical modeling served as one such reflective activity. In particular, using the modeling as vehicle approach (Galbraith et al., 2010), with a focus on the initial stages of the modeling process, before any on-site visit, participants were tasked with identifying all variables that should be considered when making decisions about energy. This challenge provided participants a lens through which to approach the educational experiences as well as to reflect upon what they had learned. Returning to initial stages of modeling as one of the concluding activities of the summer PD allowed participants to summatively reflect upon and synthesize their conceptions of energy.

Post-assessments and survey responses revealed that many participants had developed more complex and informed conceptions of the various energy sources (Loucks-Horsley et al., 2010). The post-assessments showed a general increase in participants' identification of environmental costs of energy production as well as more sophisticated representations of how the energy was produced. Survey responses demonstrated that many participants perceived energy quite differently after the summer PD. Participants reported corrected misconceptions, richer understandings, and recognition of their own and others' biases regarding energy. More importantly, participants communicated an understanding that competing agendas and perspectives on energy were not, by definition, right or wrong (Baimbridge, 2004). Instead, participants recognized that competing perspectives might all have elements of truth to them and each decision about energy could have both positive and negative outcomes for various interested parties, reflective of the ecological modernization perspective (Garner, 2004).

The increased understandings that participants revealed in the post-assessment and surveys had implications for their classroom practice as well. Many participants alluded to how their developed understanding of energy allowed them to teach about energy issues with more confidence and in a more comprehensive way (NAAEE, 2004). The PD, guided by the critical features for EE for teachers, also influenced their pedagogical approaches (Loucks-Horsley et al., 2010; Rebar \& Enochs, 2010). Participants expressed the desire to incorporate experiential learning in their classrooms. While some recognized the constraints of taking students on off-site field trips, many reported how they strived to bring the experiences into their classrooms via videos and photos of their experiences, guest speakers, and personal testimonies of what they had learned, representing the expanded view of experiential learning (Boud et al., 1985; Moon, 1999).

Perhaps the greatest impact of the PD on the participants' classroom practices was the reported goal of developing their students' critical thinking skills about socio-scientific issues and helping students to recognize agendas and biases regarding them by incorporating both content knowledge and process skills (Bodzin at el., 2010). This desire to elevate their students' learning regarding energy issues, in hopes of developing a more informed citizenry (Bloom et al., 2010; Carter \& Simmons, 2010; Winther et al., 2010), represents a transformation in the participants' own ideas about the teaching and learning of science. 


\section{CONCLUSION}

Authentic experiential learning can greatly contribute to developing environmental literacy. However, there is much more to experiential learning than merely visiting a site or witnessing a process. Instead, experiential learning opportunities must be multifaceted (e.g., site visits, video and textual resources, expert lectures, simulations, and reflective dialogue) and thoughtfully designed to expose learners to the complexities of the phenomenon under study and include multiple opportunities to reflect upon what is being learned. The PD described here focused on energy literacy and incorporated such authentic experiential learning opportunities. The PD resulted in positive growth in participants' ability to critically evaluate the environmental impacts of energy production and influenced their classroom teaching to foster similar critical thinking skills among their students. Such impact in science instruction can greatly contribute to an informed, environmentally-literate citizenry.

\section{ACKNOWLEDGEMENTS}

The professional development described in this paper was funded through the Texas Higher Education Coordinating Board and the Teacher Quality Enhancement grants program.

\section{REFERENCES}

Baimbridge, M. (2004). Towards a new economics. In J. Blewitt \& C. Cullingford (Eds.), The sustainability curriculum: The challenge for higher education (pp. 166-178). London, UK: Earthscan.

Berlin, D. F. (2014). Place-based education: Connecting mathematics, science, community, and culture. In D. F. Berlin \& A. L. White (Eds.), Initiatives in mathematics and science education with global implications (pp. 107117). Columbus, $\mathrm{OH}$ : International Consortium for Research in Science and Mathematics Education.

Bloom, M. A., Holden, M. E., Sawey, A. T., \& Weinburgh, M. H. (2010). Promoting the use of outdoor learning spaces by K-12, in-service science teachers through an outdoor professional development experience. In Bodzin, A. M., Klein, B. S., and Weaver, S. (Eds.), The inclusion of environmental education in science teacher education (pp. 97-110). https:// doi.org/10.1007/978-90-481-9222-9_7

Bloom, M. A., Quebec Fuentes, S., Feille, K. K., \& Holden, M. E. (2015). Exploring the politics and sustainability of energy production: A professional development program for science teachers. Journal of Sustainability Education, 8.

Blum, W., \& Niss, M. (1989). Mathematical problem solving, modeling applications, and links to other subjects state, trends and issues in mathematics instruction. In W. Blum, M. Niss, \& I. Huntley (Eds.), Modelling, applications and applied problem solving: Teaching mathematics in a real context (pp. 1-21). Chichester, England: Ellis Horwood Limited.

Bodzin, A. M., Klein, B. S., \& Weaver, S. (2010). Preface. In A. M. Bodzin, B. S. Klein, \& S. Weaver (Eds.), The inclusion of environmental education in science teacher education (pp. v-xiv). Dordrecht, The Netherlands: Springer. https: / / doi.org/10.1007/978-90-481-9222-9

Boorman, J. (Director/producer). (1972). Deliverance. [Motion picture]. Elmer Productions.

Boud, D., Keogh, R., \& Walker, D. (1985). Reflection: Turning experience into learning. New York, NY: RoutledgeFarmer.

Bybee, R., McCrae, B., \& Laurie, R. (2009). PISA 2006: An assessment of scientific literacy. Journal of Research in Science Teaching, 46(8), 865-883. https://doi.org/10.1002/tea.20333

Carson, R. (1962). Silent spring. Boston, MA: Houghton Mifflin Company.

Carter, R. L., \& Simmons, B. (2010). The history and philosophy of environmental education. In A. M. Bodzin, B. S. Klein, \& S. Weaver (Eds.), The inclusion of environmental education in science teacher education (pp. 3-16). Dordrecht, The Netherlands: Springer. https:/ / doi.org/10.1007/978-90-481-9222-9_1

Friedman, T. L. (2008). Hot, flat, and crowded: Why we need a green revolution and how it can renew America. New York, NY: Farrar, Straus and Giroux.

Further Education Curriculum and Development Unit (FEU). (1981). Experience, reflection, learning. London, England: Department of Education and Science, Further Education Unit.

Galbraith, P. L., Stillman, G., \& Brown, J. (2010). Turning ideas into modeling problems. In R. Lesh, P. L. Galbraith, C. R. Haines, \& A. Hurford (Eds.), Modeling students' mathematical competencies (pp. 133-144). New York, NY: Springer. https://doi.org/10.1007/978-1-4419-0561-1_11

Garner, R. (2004). Politics and sustainable development. In Blewitt, J. \& Cullingford, C. (Eds.), The sustainability curriculum: The challenge for higher education, 208-217. London, UK: Earthscan. 
Garvey, D. (2013). Only experience can bring us to the truth. Journal of Sustainability Education, 5.

Geller, P. (Director/producer), \& Evans, M. (Producer). (2009). Coal Country [Motion picture]. Laurel, MD: Evening Star Productions.

Glaser, B. G., \& Strauss, A. L. (1967). The discovery of grounded theory: Strategies for qualitative research. New Brunswick, NJ: Aldine Transaction.

Haines, C. R., Galbraith, P. L., Blum, W., \& Khan, S. (2007). Mathematical modeling (ICTMA 12): Education, engineering and economics. Chichester, UK: Horwood Publishing.

Itin, C. M. (1999). Reasserting the philosophy of experiential education as a vehicle for change in the $21^{\text {st }}$ century. The Journal of Experiential Education, 22(2), 91-98. https:/ / doi.org/10.1177/105382599902200206

Klosterman, M., Sadler, T., \& Brown, J. (2012). Science teachers' use of mass media to address socio-scientific and sustainability issues. Research in Science Education, 42(1), 51-74. https:/ / doi.org/10.1007/s11165-011-9256-Z

Kolb, D. A. (1984). Experiential learning: Experience as the source of learning and development. Englewood Cliffs, NJ: Prentice-Hall.

Lederman, N. \& Abd-El-Khalick, F. (1998). Avoiding denatured science: Activities that promote understandings of the nature of science. In McComas, W. F. (Ed.), The nature of science in science education: Rationales and strategies (pp. 83-126). Dordrecht, The Netherlands: Kluwer Academic Publishers.

Louckes-Horsley, S., Stiles, K. E., Mundry, S., Love, N., \& Hewson, P. W. (2010). Designing professional developments for teachers of science and mathematics. Thousand Oaks, CA: Corwin.

Maaß, K. (2006). What are modeling competencies? ZDM Mathematics Education, 38(2), $113-142$. https:// doi.org/10.1007/BF02655885

Medrick, R. (2013). Experiential education for change. Journal of Sustainability Education, 5.

Moon, J. A. (1999). Reflection in learning \& professional development: Theory \& Practice. London, UK: Kogan Page.

Moscardini, A. O. (1989). Identification and teaching of mathematical modelling skills. In W. Blim, M. Niss, \& I. Huntley (Eds.), Modelling, applications and applied problem solving: Teaching mathematics in a real context (pp. 36-42). Chichester, UK: Ellis Horwood Limited.

Munakata, M. (2006). A little competition goes a long: Holding a mathematical modeling contest in your classroom. Mathematics Teacher, 100(1), 30-39.

National Council for Teachers of Mathematics (NCTM) (2000). Principles and standards for school mathematics. Reston, VA: Author.

National Governors Association (NGA) Center for Best Practices, \& Council of Chief State School Officers (CCSS0) (2010). Common Core State Standards Mathematics. Washington, D.C.: Author.

National Research Council (2010). Inquiry and the national science education standards: A guide for teaching and learning. Washington, D.C.: National Academy Press. https:// doi.org/10.17226/9596

NGSS Lead States (2013). Next generation science standards: For states, by states. Washington, DC: National Academy Press.

North American Association for Environmental Education (2004). Environmental education materials: Guidelines for excellence. Retrieved from https://cdn.naaee.org/sites/default/files/gl_ee_materials_complete.pdf

Novak, D. (Director/producer), Rosenfeld, D. (Producer), Follini, C. J. (Producer), \& Zoullas, A. (Producer). (2008). Burning the Future: Coal in America [Motion picture]. New York, NY: New Video Group, Inc.

Parker, J., Wade, R., \& Atkinson, H. (2004). Citizenship and community from local to global: Implications for higher education of a global citizenship approach. In J. Blewitt \& C. Cullingford (Eds.), The sustainability curriculum: The challenge for higher education (pp. 63-77). London, UK: Earthscan.

Pollak, H. O. (2011). What is mathematical modeling? In H. Gould, D.R. Murray, A. Sanfratello, \& B.R. Vogeli (Eds.), Mathematical modeling handbook (pp. vi-vii). Bedford, MA: COMAP.

Rebar, B. M., \& Enochs, L. G. (2010). Integrating environmental education field trip pedagogy into science teacher preparation. In A. M. Bodzin, B. S. Klein, \& S. Weaver (Eds.), The inclusion of environmental education in science teacher education (pp. 111-126). Dordrecht, The Netherlands: Springer. https:/ / doi.org/10.1007/978-90-4819222-9_8

Saylan, C., \& Blumstein, D. T. (2011). The failure of environmental education [and how we can fix it]. Berkeley, CA: University of California Press.

Slattery, M. (2015). Afterword. In Stratton, S., Hagevik, R., Feldman, A., \& Bloom, M. (Eds.), Educating science teachers for sustainability (pp. 459-468). Dordrecht, the Netherlands: Springer. 
Texas Comptroller of Public Accounts. (2008). The Energy Report 2008. Retrieved from http:/ / www.window.state.tx.us/specialrpt/energy/

Thomas, D. R. (2006). A general inductive approach for analyzing qualitative evaluation data. American Journal of Evaluation, 27(2), 237-246. https:/ / doi.org/10.1177/1098214005283748

Winther, A. A., Cleary Sadler, K., \& Saunders, G. (2010). Approaches to environmental education. In A. M. Bodzin, B. S. Klein, \& S. Weaver (Eds.), The inclusion of environmental education in science teacher education (pp. 31-50). Dordrecht, The Netherlands: Springer. https:/ / doi.org/10.1007/978-90-481-9222-9_3

\section{http://www.ejmste.com}

